\title{
Quality of Human Resources in Europe Measured by Selected Indicators of Human Potential
}

\author{
Slavomir Bucher \\ Pavol Jozef Šafárik University, Slovakia
}

\section{Introduction}

The aim of the article is to identify selected indicators the quality of life and its subsequent aggregate into the index of human potential using the comparative analysis in Europe. The paper is also trying to present research evaluation of human potential indicators regarding the sustainable development in Europe. The population is defined as a group of people living in a given territory and under its jurisdiction. Those two factors remain despite technological progress the most important determinations for the overall development of the region. Basic characteristics of population - the total number of population; spatial distribution; various structural patterns - belong to as an important prerequisite for assessment of the social and economic activities in the region. Growth or decline rate the number of the population may be a stimulating or limiting factor for economic growth in the particular country and its regions.

Population growth allows countries aggregate their expenditure and promote the development of the economy, but for developing countries population growth exacerbates spiral issue with poverty and weaknesses accelerated by austerity measures of financing and social services that provide particular social activities in education and general health care system (McKendrick, 1999; Sić, 2003).

Primarily attention is focused on axiology of understanding the quality of human resources based on the premise that crucial issue related to the quality of human resources are the result of an appropriate evaluation of human potential indicators (Diener \& Suh, 1997; Lutz, 2009).

Selection of variables which will be involved in the creation of aggregate indicator must comply with the criteria of internal and external validity to facilitate analysis and interpretation the complexity of demographic phenomenon and processes. The quality of human resources is measured indirectly using reliable indicators and components. According to the definition, the indicator has to reflect the condition and status of the phenomenon at a certain period. Thus, understanding the definition of regional disparities based on the well-chosen criteria, particularly, the 
objective pursued, scale, the notice capability of indicators, possibilities for evaluation, availability of resources and statistical data as well (Brülhart, Traeger, 2005).

As an important component of human potential is demographic resources which comprehensively include qualitative and quantitative, social and biological characteristics of the population in time and space (Findlay \& Hoy, 2000; Graham, 2000; Bailey, 2005). The demographic potential has a direct impact on the socioeconomic structure and processes in human society - for example, population ageing affects the social and economic development of the region. Post-productive population with difficulties accept changes that are the result of the social and economic transformation; elderly people less flexible react and adapt to new trends in society and refuse innovations in the economy and business as well. The current demographic potential of Europe could be described as a satisfactory, but we cannot underestimate negative processes that impacted with different intensity countries across the Europe. Among the processes which negatively influence on demographic sustainability place: (bio)reproductive depopulation, rural-urban socio-economic segregation, and intensification of population ageing (Goldscheider, 2014; Bernardi \& Hutter, 2007). In Eastern Europe, we reflect disparities formed as a consequence of processes related to deindustrialization, urbanisation, uneven distribution of the population in regions, migration associated with social and economic instability. Referenced socio-demographic processes negatively contribute to the reduction of "human capital." Human capital is the one of the essential elements of socio-economic development in the region. There are many regions in Europe where the population is characterised by negative biological balance and low education status. Both characteristics present limiting factors for the sustainable development of the region. Following the general development trends alongside with unfavourable demographic processes, assume that in the coming years could expect an intensification of negative demographic phenomenon leading to the socio-economic stagnation in peripheral regions of Europe. For the reduction of socio-economic disparities, the main objective is to maximise endogenous regional potential including demographic resources. Therefore, it is necessary to define clearly the relevant causes and consequences leading to declining demographic and socio-economic inequality in Europe. Development of synthetic indicators allows us identifying regions with different level of demographic potential and subsequently applied methods to its stabilisation.

In a literature review, observing some examples dealing with synthetic indicators (Booysen, 2002; Dwyer \& Kim, 2003; Michalek, 2013), which combine social, demographic and economic characteristics of inequality in regions. The most recognisable synthetic indicator is Human Development Index (HDI), which represents a summary measure of average achievement in key dimensions of human development: a long and healthy life, being knowledgeable and have a decent standard of living. Comparison of the four HDI components can be 
measured and evaluated levels of social and economic development. A limited number of selected variables as input for measurement of HDI indicates that Human Development Index is predominantly used for global comparison analyses.

It is necessary to remark on the certain shortage of quality and reliability comparing various synthetic indicators that evaluate socio-economic and demographic potential of the region. Thus, following researchers (e.g. Nejašmić, 2002; Lutz, 2009; Cohen, 2000) providing both essential overviews about identification and analysis of demographic potential, and methodological framework for next research on this issue. Unfortunately, based on literature overview could not be able to identify a single framework for our research. Presenting papers elaborate their research of human potential on different often disparate approaches and concepts. For identification, analysis and evaluation demographic potential elaborating only a limited range of works that are also involved spatial (geographical) dimension quality of human potential.

Contributions concentrating on theoretical phenomenon and selection of relevant indicators for spatial and regional disparities research are presented in papers (Cai, Wang \& Du, 2002; Duranton \& Overman, 2005; Michalek \& Podolak, 2010; Huang \& Leung, 2009; Novotny \& Nosek, 2012 and Michalek \& Podolak, 2010) identify a comprehensive assessment of socio-economic disparities using "negative" demographic characteristics that indicate negative aspects of inequality and human potential in regional populations. Recently, new demographic characteristics and indicators emerge which significantly influence on measurement and assessment of human resources and human potential.

\section{Methodology}

In article use available methods for measurement the indicators of human potential. Likewise, the paper describes chosen indicators and assesses the selected European countries according to results based on sub-indicators values. What's more, the general benefit of our contribution is a mutual comparison of selected countries according to sub-indicators of human potential. Selected indicators quality of human potential for input analyses were based on a survey published by Yale Center for the Environmental \& Policy, Yale University and the Center for International Earth Science Information Network, Columbia University, in collaboration with World Economic Forum in Geneva.

Due to the absence of relevant data following countries have been excluded from the further analysis: Andorra, Liechtenstein, Monaco, San Marino, Vatican City, and for certain indicators Belarus as well. Significantly, Aggregate Index together with Human Development Index entered into the linear regression as the dependent variable. The following set of indicators measured at country level represent Aggregate Index of Human Potential: 
$\checkmark$ Ageing Index $2010-2015(\%)$, is calculated as some persons 65 years old or over per hundred persons under age 15 . Values of the ageing index are in direct relation to the aging of the population.

$\checkmark$ The Youth Dependency Ratio $2010-2015$ (\%), is the number of persons 0 to 14 years per one hundred persons 15 to 64 years.

$\checkmark$ Life Expectancy at Birth 2010 - 2015, simple definition of life span - it represents a summary of mortality rate, does not use a standard population. Therefore, it can be readily compared to countries and regions. There is a limitation of health reliability of the values presenting by standardized mortality rate.

$\checkmark$ Human Resources TTCI 2013, Quality of human potential was assessed in the Travel \& Tourism Competitiveness Report provided by World Economic Forum. Indicator represents one of the fourteen dimensions of Travel \& Tourism Competitiveness Index (TTCI). The methodological approach of the index is based on detection relations between individual elements of socio-economic spheres, i. e. the quantification of links between industrialization, urbanization, the socioeconomic and demographic structure of the population, as well as the living standards. Named indicator shall specify education and training, as well as ensure measurement of quality of education system. Besides the formal education also takes into the account an importance of dual education with private sector participation in order to increase skills and practical experiences of the labor force.

$\checkmark$ Health and Primary Education GCI 2014 - 2015, as one sub-index of Global Competitiveness Index (GCI), carried out under the World Economic Forum (Schwab, 2014). In order to analyze the health and primary education in Europe, GCI sub-index was implemented in our research. Basic education increases the efficiency of each person. Moreover, often persons who received little formal education can carry out only simple manual tasks and find it much more difficult to adapt to more advanced production processes and techniques, and therefore they contribute less to executing innovations. Several socio-pathological phenomena in society, such as poverty, civilization diseases, environmental degradation and socio-economic inequality of selected groups of the population are closely linked to the quality of care and educational activities. Health and Primary Education Indicator allow us to detect the specific mosaic level of competitiveness in the social and educational system in European countries.

$\checkmark$ Infant Mortality Rate 2010 - 2015, is defined as the ratio of the number of deaths in the first year of life to the number of live births occurring in the same population during the same period. Infant mortality represents one of the most important indicators of socio-economic development and quality of public health services.

$\checkmark$ Human Development Index 2013, is calculated as a composite index measuring average achievement in three basic dimensions (4 indicators) of human development; long and healthy life (life expectancy at birth), education (mean and expected years of schooling), and a decent standard of living (gross national income per capita). The index ranges from $0-1$, with a higher score reflecting a higher degree of human development (Newbold, 2013). 
All indicators have been assigned the same weight. From such prepared analysis of indicators at the level of countries were calculated the values of the index of Aggregate Index of Human Potential. It consists of seven indicators transformed to consisted scale $<0,1\rangle$ according to the formulas cited in the work by (Murgaš, Klobučník, 2014): $Z_{\mathrm{io}}=\left(X_{\mathrm{io}}-X_{\text {min. }}\right) /\left(X_{\text {max. }} . X_{\text {min. }}\right)$, in the case that the desired rating of the phenomenon increased with increasing value of $x_{i o}$ or $Z_{i o}=\left(X_{\text {max. }} X_{i o}\right) /\left(X_{\text {max.- }}\right.$ $X_{\text {min. }}$.) in the case that the desired rating of the phenomenon increased with decreasing value of $x_{\text {io. }}$.

\section{Empirical analysis of human potential in europe}

The first analyzed indicator is Ageing Index. It represents one of the sub-indicators measurement of human potential and endogenous development of the region. Analyzed countries according to achieved values of the Ageing Index are significantly spatially differentiated. Spatial distribution of Ageing Index is characterized by a strong north-southern and west-eastern gradient in Europe. The results show that selected countries in western and southern Europe were recorded high values of Aging Index, whereas most of these countries have regressive population pyramid with a declining birth rate and a low mortality rate. Named countries and regions have lower than average percentage of youth people, which is directly linked with sharp reduction of natural increase.

The most favorable results (table 1), the lowest values of the Ageing Index during the observed period were recorded in Turkey (11.1\%), and Moldova (13.6\%). Turkey has different characteristic patterns of Ageing Index comparison to the rest of Europe. Therefore, above average youth component of the population as well as high values of birth rates in comparison with the rest of Europe could be caused by significantly different cultural and religious (Islam) factors. Ireland is only one western European country that shows the lowest values of the Ageing Index (18.3\%). Ireland faced since the early of the 1990s with structural economic transformation. Massive tide of foreign development investments followed up by economic reforms and attractive economic environment created Ireland key player for multinational companies such as Dell, Google or Microsoft. The Irish economy was able to use the sharp economic development of the USA in the information technologies. Ireland is transformed into the technology center of Europe, what caused the risen of living standard its inhabitants. Moreover, higher quality of social and health services eventuated to increase natality rate and immigration mostly from central and eastern Europe. The dominant position of the Catholic Church in society, legislative and legal norms in the area of health and social custody significantly influence on high birth rates in Ireland. Ireland belonged to one of the last European countries that legalized abortion (Schwab, 2014). 
On the other hand, the highest values of Ageing Index (figure 1) report countries located in a southern and western part of Europe - Italy (33.2\%) and Germany (31.8\%). High values of the Ageing Index in Germany and Italy could be justified by low birth rate, which has a decisive importance in reproduction process and natural growth of population. Bulgaria located in south-eastern Europe is an example with the highest values of Ageing Index among the observed countries. In Bulgaria, there were 29 elderly people per 100 people aged 0-14 (average $2010-$ 2015). The high values of this variable in Bulgaria are the result of growing gap in social and economic disparities, which have a negative influence on young people who postpone the decision for parenthood. Furthermore, the considerable factor which affects high values of the Ageing Index is a negative migration flow of economically active component of the population out of Bulgaria, mostly to Western Europe (Lutz, 2009).

The second analyzed indicator is Youth Dependency Ratio (table 1). Population structure according to age is used as an input for a whole range of other demographic and geographical characteristics. In contrast to the large group of phenomena, which are otherwise applied to a segment of the population (mortality, natality, etc.), shaping age structure and its changes affecting all population. Moreover, population structure according to age may significantly affect the progress of any demographic related phenomena and processes. Based on Youth Dependency Ratio, analyzed countries demonstrate significantly different values regarding the share of the productive and post-productive population.

The most favorable results, therefore, the highest share of younger dependents people (0-14) to the working-age population - those ages 15-64 showed the following countries: Turkey (39.6\%), Ireland (32.0\%) and Albania (29.3\%). On the other hand, the lowest values of Youth Dependency Ratio during the considered period were registered in Bosnia and Hercegovina (19.7\%), Germany (20.1\%), and Ukraine (20.6\%). These results could be interpreted precisely by getting appropriate data about age and sex categories of the population for selected countries. An important role, in this case, plays development of younger dependents and working-age categories, birth rate, and life expectancy at birth. Turkey and Albania occupied the last place in the rating of life expectancy and share of the post-productive group on total population.

With this in mind the Youth Dependency Ratio demonstrates importance of youth age category group (0-14) which is important for the creation of further economic progress in society. Unfortunately, expression of Youth Dependency Ratio is rather than misleading, because we cannot clearly demonstrate the quality of human potential, but an Aggregate Index would give as a tool for deeper understanding differentiation of human potential in Europe. 
The third indicator forming to the Aggregate Index of Human Potential represent Life Expectancy at Birth (table 1, figure 1). Life Expectancy at Birth belongs to a group of indicators with a high level of spatial interpretation. It is the most frequently used characteristics of a productive component of the population. There is a differentiation between both genders according to average Life Expectancy at Birth for men and women. Thus, indicator values are given separately for each gender. The average Life Expectancy at Birth $(2010$ - 2015) for both sexes is the lowest in the Russian Federation (68.9 years) and Ukraine (70.8 years). The primary reason for the lowest values of Life Expectancy is related to economic and social inequality in society; lack of health and geriatric services for the elderly population and unhealthy habits associated with civilization modern diseases. Contrary, the highest score according to analyzed countries have been reached Italy (82.8 years) and Switzerland ( 82.7 years).

The following two indicators - Human Resources TTCI 2013 and Health and Primary Education GCI 2014 - 2015 (table 1, figure 1, 2) define the structure of population according to the economic activities, and cultural patterns. Education structure as one of the qualitative pattern of the population has to the economic development of the region the most significant impact. Both indicators are among the most important determinants of the population considering socio-demographic aspects, as they affect all spheres of social life. Insufficient education not only reduces opportunities on labor market but also it is responsible for worsening living conditions, increasing social risks and exacerbating the health situation of the population.

Human Resources TTCI 2013, as a partial indicator of Travel and Tourism Competitiveness Index, closely characterize human resources, which are essential for building the knowledge-based oriented economy. Importantly, knowledgebased society requires the definition of a new framework and learning concept based on current conditions and positive trends in society. Thus, it is necessary to increase the education level of economically active population, elaborate good accessibility to educational institutions, support a growing interest in non-formal education and training activities especially in the field of languages, management, and information and communication technologies (Blanke \& Chiesa, 2013).

The highest score of Human Resources TTCI 2013 indicator was obtained in Switzerland (6.11) following by Iceland (5,84). Governments of countries located in northern and western Europe enforce a comprehensive approach to increasing quality of educational processes, which represent an important factor for building a knowledge-based society. Modernization processes of education infrastructure in schools and universities contribute to developing educational system following principles of Lisbon Agenda to make the $\mathrm{EU}$ "the most competitive and dynamic knowledge-based economy in the world capable of sustainable economic growth with more and better jobs and greater social cohesion". The lowest values of 
indicator were observed in Moldova (4.51) and Serbia (4.63); all region of eastern Europe is struggling with corruption and inadequate investments in modernizing the education process.

Following indicator Health and Primary Education GCI, which is part of the Global Competitiveness Index record services in the area of health care and primary education. Quality and accessibility of primary education have an indirect influence on the performance of the economically active population. Several sociopathological phenomena in society, such as poverty, civilization diseases, environmental degradation and socio-economic exclusion of selected groups of the population, are closely linked to the quality of health care and education activities (Goldscheider, 2014). The highest health standard and primary education were reported in Finland (6.22) and the Netherlands (5.99). On the opposite side of the spectrum were placed countries as Georgia (3.89) and Moldova (4.08). The indicators of Health Quality and Primary Education were obtained from Global Competitiveness Report 2014 - 2015, published by International Economic Forum (Schwab, 2014).

Infant Mortality Rate 2010 - 2015 represents the last indicator entering to the calculation of the Aggregate Index of Human Potential (table 1). Significantly, indicator expresses the death of a child less than one year of age. The complexity of this indicator is contained in a very complicated context of sub-processes with many social phenomena, especially in historical and spatial patterns. The highest values obtained countries in south-eastern Europe. The main reason of unfavorable Infant Mortality Rate has been associated with social, health and economic situation resulting in the above average values of Infant Mortality, compared to the rest of Europe. On the other hand, the lowest values of indicator were recorded in western and northern Europe (range $2-4 \%$ ). The low values of Infant Mortality are caused by high-quality of social and health care services in this countries.

Above all, European population has got to the next stage its long-term demographic development, which is characterized by a significant change in the values of selected indicators. Notwithstanding except the chosen sociodemographic indicators that affect to regional differences in Europe, we also evaluated human potential through comprehensive Aggregate Index of Human Potential. In conclusion, named indicator reflects the regional disparities considered the quality of human development through six socio-demographic indicators (table 2). 


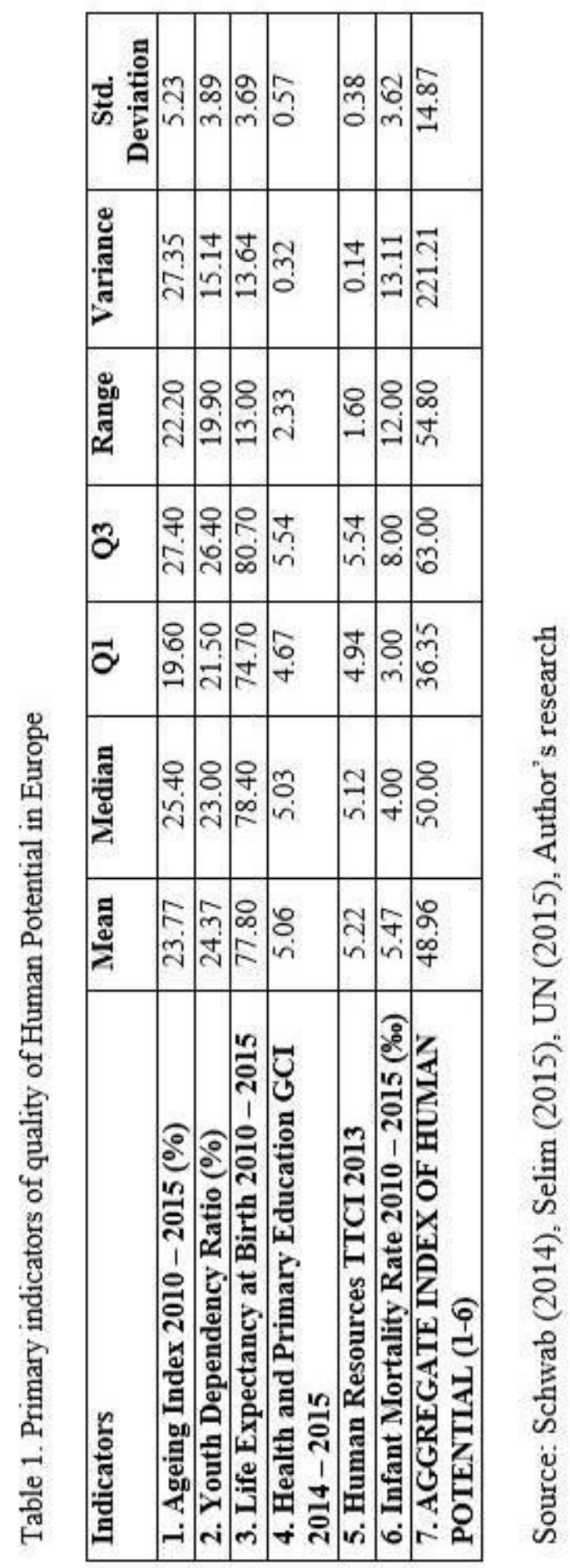




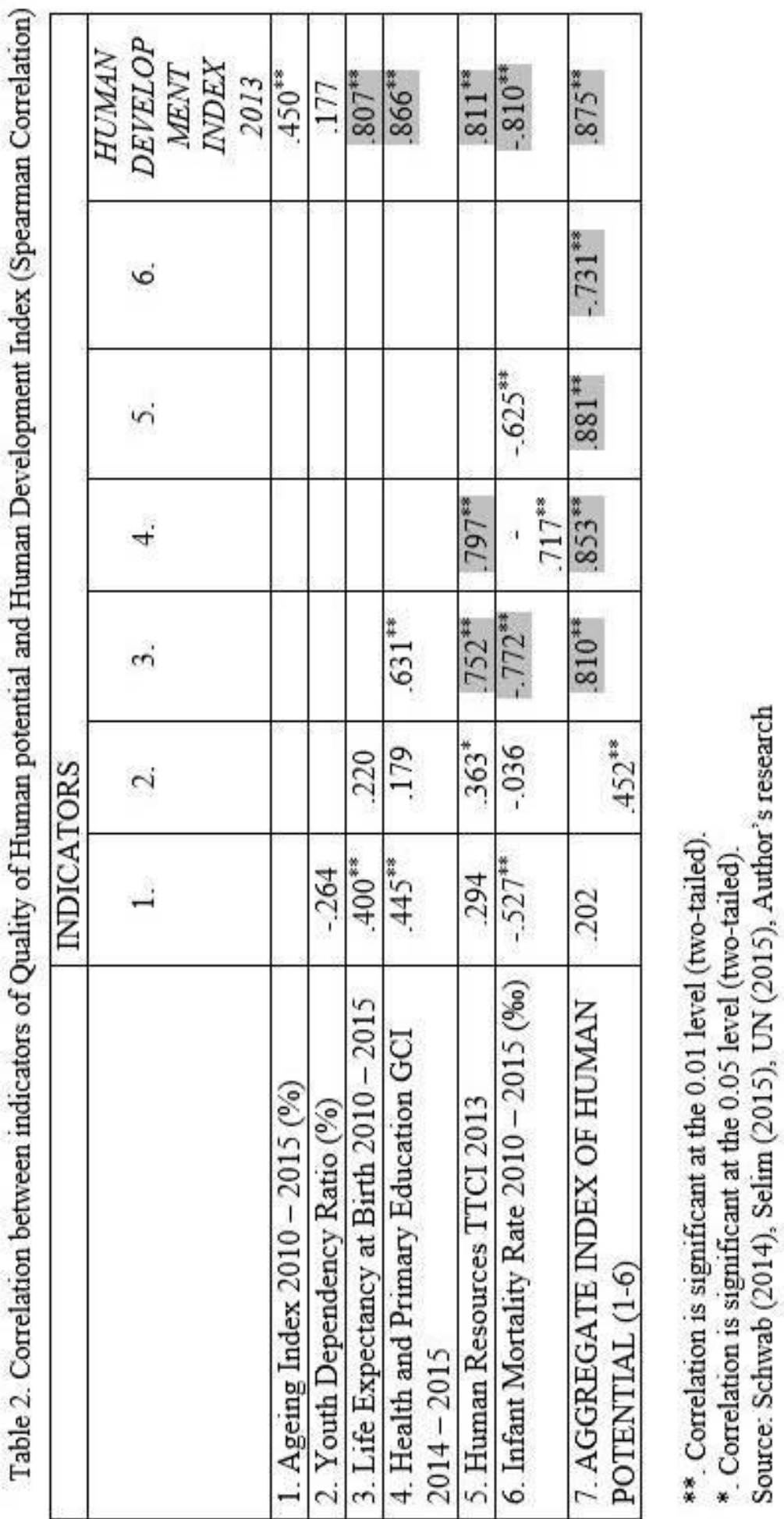



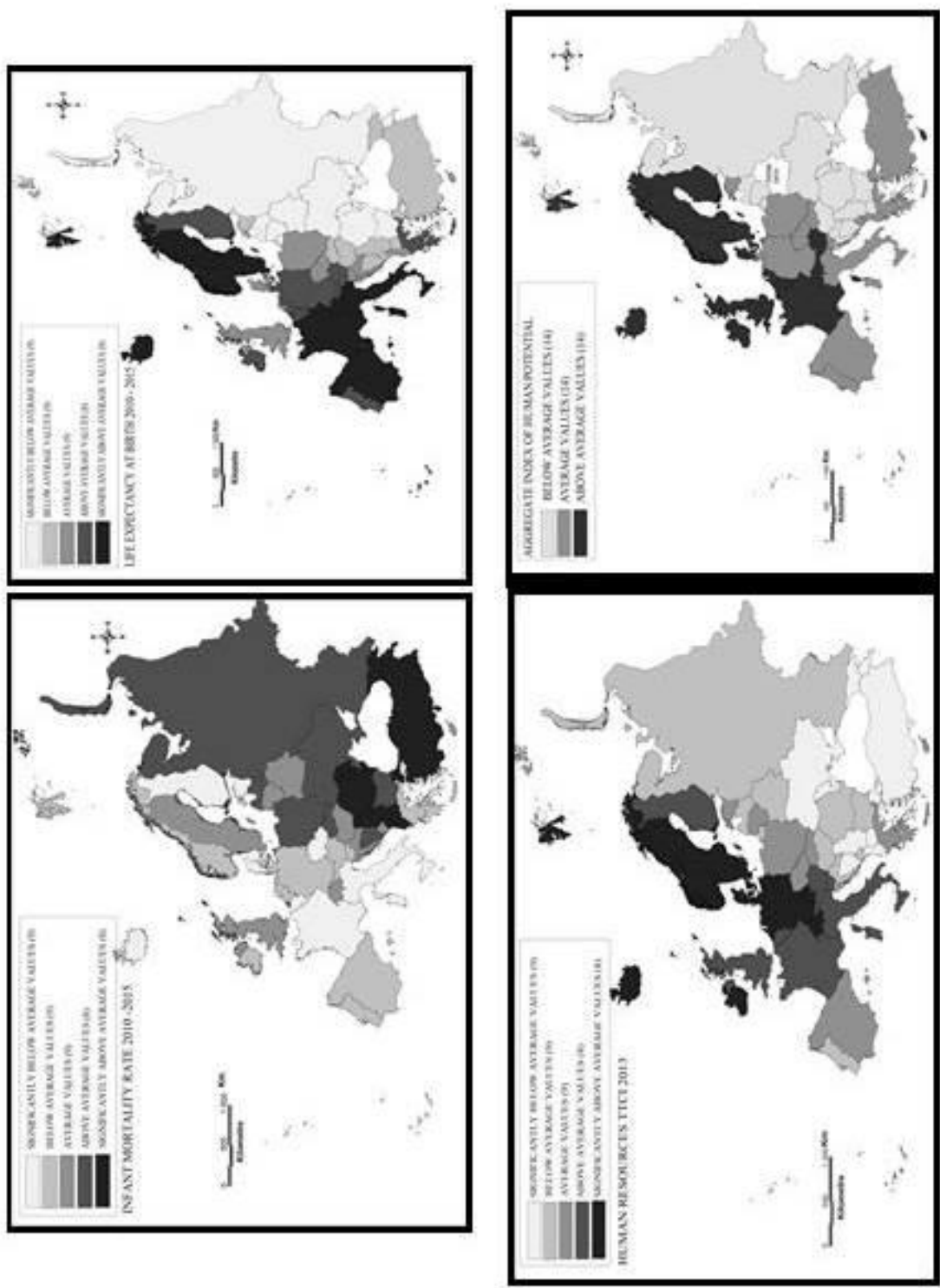

章

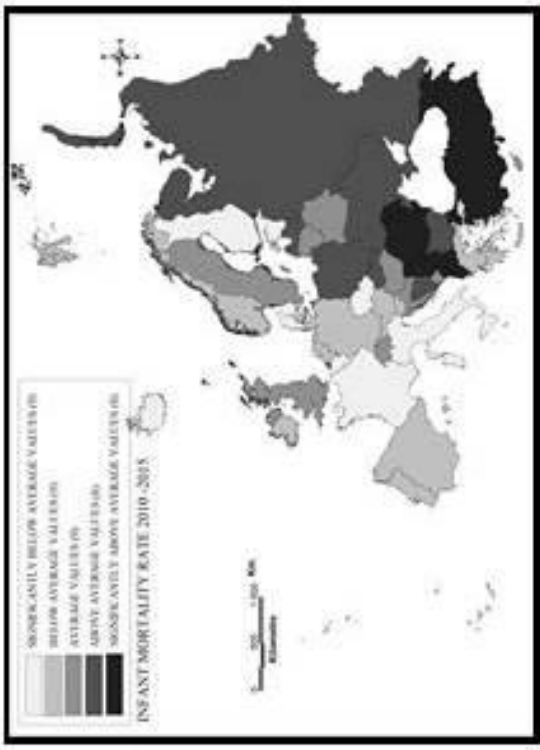

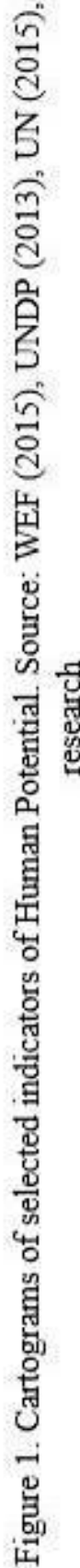



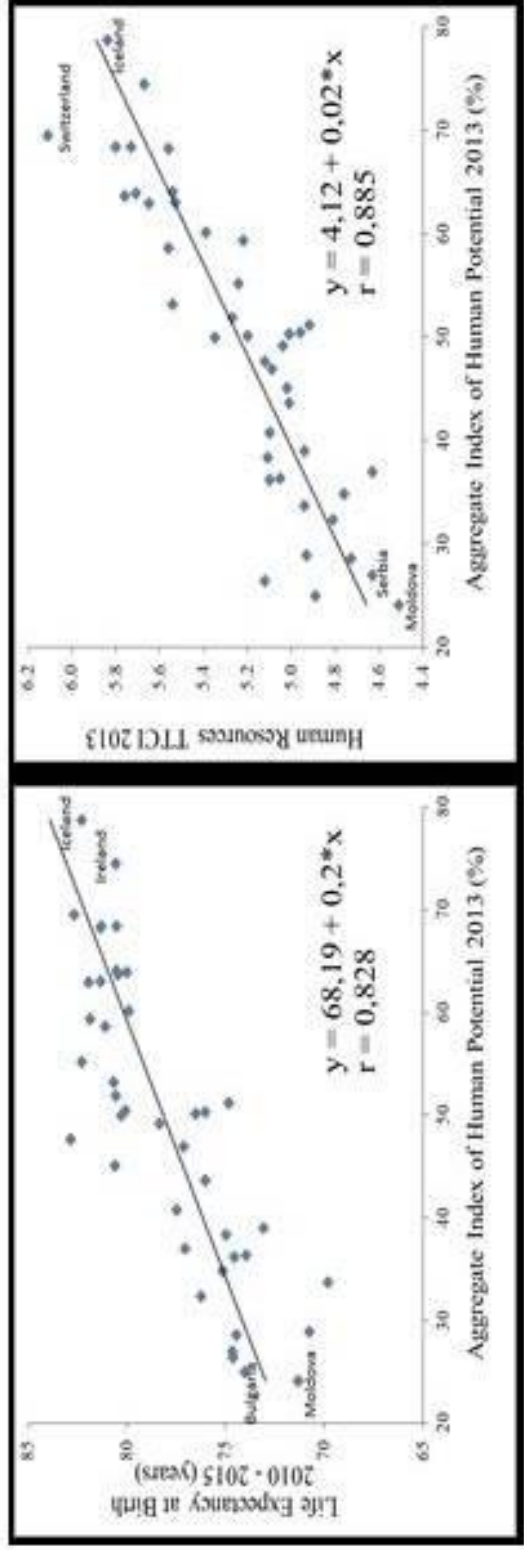

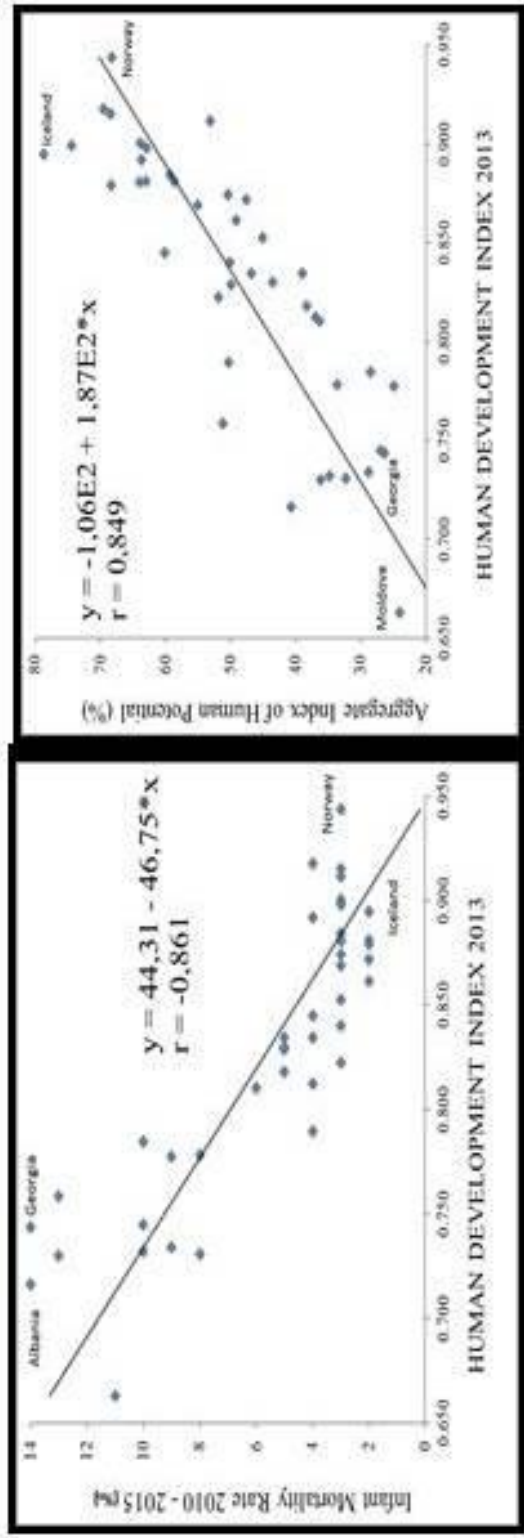

䕎

营

窇

농

䓈 造

至

量

붕용

릉

ㅁำ

欹

ติำ

15

क ฮ

窑只

苛 5

볼

롱

牙

욜

5

क्ष

.

㝴

용

过

क

茨

동

争

옹

ำ 
Table 3. Aggregate Index of Human Potential and Human Development Index in relation to socio-demographic indicators

\begin{tabular}{|c|c|c|c|c|c|c|c|}
\hline & \multicolumn{3}{|c|}{$\begin{array}{l}\text { AGGREGATE INDEX OF } \\
\text { HUMAN POTENTIAL }\end{array}$} & \multicolumn{4}{|c|}{$\begin{array}{c}\text { HUMAN DEVELOPMENT } \\
\text { INDEX (2013) }\end{array}$} \\
\hline Sig. $<0,000$ & $\mathrm{~B}$ & $\begin{array}{c}\text { Std. } \\
\text { Deviation }\end{array}$ & Beta & $\mathrm{B}$ & $\begin{array}{l}\text { Std. } \\
\text { Devia } \\
\text { tion }\end{array}$ & Beta & Sig. \\
\hline (Constant) & 1.357 & .016 & & .255 & .125 & & .049 \\
\hline $\begin{array}{l}\text { 1. Ageing Index } \\
2010-2015(\%)\end{array}$ & .007 & .000 & -.265 & .001 & .001 & .108 & .191 \\
\hline $\begin{array}{l}\text { 2. Youth } \\
\text { Dependency Ratio } \\
(\%)\end{array}$ & .008 & .000 & .221 & .001 & .001 & .087 & .239 \\
\hline $\begin{array}{l}\text { 3. Life Expectancy } \\
\text { at Birth } 2010 \text { - } \\
2015\end{array}$ & .013 & .000 & .309 & .003 & .002 & .161 & .131 \\
\hline $\begin{array}{l}\text { 4. Health and } \\
\text { Primary } \\
\text { Education GCI }\end{array}$ & .071 & .002 & .271 & .019 & .015 & .163 & .199 \\
\hline $\begin{array}{l}\text { 5. Human } \\
\text { Resources TTCI } \\
2013\end{array}$ & .104 & .003 & .266 & .042 & .021 & .234 & $.052 * *$ \\
\hline $\begin{array}{l}\text { 6. Infant } \\
\text { Mortality Rate } \\
2010-2015(\%)\end{array}$ & -.014 & .000 & -.343 & -.008 & .002 & -.448 & $.000 *$ \\
\hline $\begin{array}{l}\text { Index of } \\
\text { Determination }\end{array}$ & & 1.000 & & & 0.904 & & \\
\hline
\end{tabular}

Dependent Variable: Aggregate Index of Human Potential and Human

Development Index (2013)

**. Correlation is significant at the 0.01 level (two-tailed).

*. Correlation is significant at the 0.05 level (two-tailed).

Source: WEF (2015), UNDP (2013), UN (2015)

Likewise, the results of Spearman correlation applied at the level of selected European countries is shown in table 2. Results show that Human Development Index has significant at $1 \%$ level association with all sub-indicators of Aggregate Index except the Youth Dependency Ratio. The most important relationship shows the Human Development Index and Aggregate Index (table 2). What's more, linear regression between the Human Development Index, Aggregate Index (as dependent variables) and the selected sub-indicators within the European countries is displayed in table 3. According to this model, R-square, the percent of the Human Development Index, explained by six variables is 0.904. It means that six 
independent model explain $90.4 \%$ of the variance. Data presented in table 3 also highlights the significant relationship at 0.01 level between Human Development Index, Human Resources TTCI 2013, and Infant Mortality Rate (2010 - 2015) significant at 0.05 level.

Moreover, standardized coefficient Beta (table 3) refer to how many standard deviations a dependent variable will change, per standard deviation increase in the predictor variable in regression analysis. Coefficient Beta has demonstrated the highest indirect association both in Aggregate Index of Human Potential (AIHP) and Human Development Index (HDI) with one independent variable - Infant Mortality Rate ( -0.343 for AIHP and -0.448 for HDI).

Based on primary results analyzes of Aggregation Index of Human Potential has constructed a basic typology of European countries. Spatial analysis of results showed (figure 1) that the lowest values of AIHP reached the countries located in south-eastern Europe (Moldova, Bulgaria, Serbia, Romania, Ukraine). For a presented group of countries are characterized low values of Health and Primary Education GCI indicator, Infant Mortality Rate and Life Expectancy at Birth as well. Otherwise, same countries recorded the highest values in Infant Mortality rate. The Scandinavian countries, Iceland, Norway, Finland, Western European countries such as Ireland, Switzerland, Netherlands have the highest values of AIHP indicator. The countries with the above-average values of AIHP are among the World leaders in quality of health and education, human resources and longevity of its people. They have relatively less favorable indicators measuring age structure - aging index and youth dependency ratio.

\section{Conclusion}

Based on the analysis of human potential and its quality in selected countries of Europe using the six independent variables and two dependent variables was showed that high level of regional differentiation is characterized by all social and demographic indicators entering to the analysis. Above all, the main objective of our research was concentrated on selection and comparison of appropriate sociodemographic indicators and monitoring its impact and dependency on Human Development Index. Based on results of Human Development Index we could specify linear intensity for components of Aggregate Index of Human Potential, which initiates economic and social development of the region.

In conclusion, demographic aspects of analyzed processes are not comprehensive and sufficient to overall assessment quality of human potential but significantly contribute to their analysis and understanding the context of research objectives. Therefore, was applied sub-indicators of Global Competitiveness Index (Health and Primary Education), as well as The Travel \& Tourism Competitiveness (Human Resources Index). Another set of indicators could be considered in the 
assessment of the human potential, for example (1) percentage of the population with the highest completed higher education and basic education or (2) percentage of the population with the essential IT skills.

The analysis set of indicators reveals, that country with the highest values of Aggregate Index of Human Potential are located in northern and western Europe (Iceland, Ireland, Switzerland, Netherland, Finland and Norway).

However, countries with above-average values of Aggregate Index of Human Potential maintain its position because of the high level of education and training activities, which are the basis for the qualified work force in the labor market. Highly qualified workforce stimulates the growth of the economy and helps to the cultural and social development of their regions. Having said that, analysis of human potential at the level of European countries also points to differentiated development in analyzed countries. Regional differences between analyzed countries are markedly in particular with a Life Expectancy at Birth, Ageing Index and Infant Mortality. All analyzed indicators and its mutual comparison reflect the spatial differentiation in Europe. On the one side, we can identify from the perspective of human potential rising and prosperous countries, on the other side there is declining, and underdeveloped countries combine phenomenon of depopulation, emigration and low educational level of population, which leads to poverty in economic and social aspects of sustainability. The most persuasive starting point from the current unfavorable situation of analyzed countries should be targeted process of measurements aimed at mitigating the significant economic, social and demographic differences between countries; as a result of the transformation in Central and Eastern Europe.

\section{References and notes:}

Bailey, Adrian J. Making Population Geography. London: Hodder Education, 2005.

Bernardi, Laura, Hutter, Inge. "The anthropological demography of Europe." Demography research, vol. 17, 2007, pp. 541-566.

Blanke, Jennifer, Chiesa, Thea. The Travel \& Tourism Competitiveness Report 2013. Reducing Barriers to Economic Growth and Job Creation. Geneva: World Economic Forum, 2013.

Booysen, Frederik. "An overview and evaluation of composite indices of development." Social Indicators Research, vol. 59, no. 2, 2002, pp.115-151.

Brülhart, Marius, Traeger, Rolf. "An account of geographic concentration patterns in Europe." Regional Science and Urban Economics, vol. 35, no. 1, 2005, pp. 597-624.

Cai, Fang, Wang, Ddewen, Du, Yang. "Regional disparity and economic growth in China. The impact of labor market distortions." China Economic Rewiew, vol. 13, 2002, pp. 197-212.

Cohen, Erik H. "Multi-dimensional analysis of international social indicators - Education, economy, media and demography." Social Indicators Research, 2000, vol. 50, no. 1, 2000, pp. 83-106.

Diener, Ed, Suh, Eunkook. "Measuring quality of life: economic, social, and subjective indicators." Social Indicators Research, vol. 40, no. 1, 1997, pp. 189-216. 
Duranton, Gilles, Overman, Henry G. "Testing for localisation using microgeographic data." Review of Economic Studies, vol. 72, no. 4, 2005, pp. 1077-1106.

Dwyer, Larry, Kim, Chulwon. "Destination Competitiveness: Determinants and Indicators." Current Issues in Tourism, vol. 6, no. 5, 2003, pp. 369-414.

Findlay, Allan M., Hoy, C. "Global population issues: towards a geographical research agenda." Applied Geography, vol. 20, no. 3, 2000, pp. 207-219.

Goldscheider, Frances K. "The Demography of Europe." European Journal of Population Revue Europeenne de Demographie, vol. 29, no. 4, 2014, pp. 493-495.

Graham, Elspeth. "What Kind of Theory for What Kind of Population Geography?" International Journal of Population Geography, vol. 6, no. 4, 2000, pp. 257-272.

Huang, Yefang, Leung, Yee. "Measuring regional inequality: a comparison of coefficient of variation and Hoover concentration index." The Open Geography Journal, vol. 2, 2009, pp. 25-34.

Lutz, Wolfgang. "The Demography of Future Global Population Aging: Indicators, Uncertainty, and Educational Composition." Population and Development Review, vol. 35, no. 2, 2009, pp. 357-365.

McKendrick, John H. "Multi-Method Research: An introduction to its Application in Population Geography." The Professional Geographer, vol.51, no.1, 1999, pp.40-50.

Michalek, Anton, Podolak, Peter. "Socio-economic disparities and migration in Slovakia." Moravian Geographical Reports, vol. 18, no. 2, 2010, pp. 36-45.

Michalek, Anton. "Identification and measurement indicators of regional disparities (some remarks on selection of indicators)." Geographical journal, vol. 65, no. 4, 2013, pp. 363-381.

Murgas, Frantisek, Klobucnik, Michal. "Municipalities and Regions as Good Places to Live:Index of Quality of Life in the Czech Republic." Applied Research Quality of Life, vol. 11, no. 2, 2016, pp. 553-570.

Nejasmic, Ivo. "Demographic Development in European Post-Socialist Countries (1990 1999)." Journal of General Social Issues, vol. 11, no. 4-5, 2002, pp. 701- 723.

Newbold, Bruce K. Population Geography: Tools and Issues. Lanham: Rowman and Littlefield Publishers, 2013.

Novotny, Josef, Nosek, Vojtech. "Comparison of regional inequality in unemployment among four Central European countries: an inferential approach." Letters in Spatial and Resource Sciences, vol. 5, no. 2, 2012, pp. 95-101.

Selim, Jahan. Human Development Report 2015. Work for Human Development. New York: United Nations Development Programme, 2015.

Schwab, Klaus. The Global Competitiveness Report 2014-2015. Geneva: World Econmic Forum, 2014.

Sic, Miroslav. "Regional disparities in Croatia." Croatian Geographical Bulletin, vol. 65, no. 2, 2003, pp. 5-28.

United Nations, Department of Economic and Social Affairs, Population Divison. World Population Prospects: The 2015 Revision, Key Findings and Advance Tables. New York: United Nations, 2015. 


\title{
Summary
}

\section{Quality of Human Resources in Europe Measured by Selected Indicators of Human Potential}

\author{
Slavomir Bucher \\ Pavol Jozef Šafárik University, Slovakia
}

The paper deals with regional differentiation of human resources and its determinants identified by selected indicators of human potential. The selection of correct and relevant indicators has a key role in the identification and measurement of human potential. The aim of the study is to outline causal and determinant relationship (the relation and the level of dependence) in the spatial differentiation of human resources in Europe and approaches to their interpretation. The main purpose of this paper is to analyze the link between human potential and quality or inequality of life and its effect on population from a demographic viewpoint. Methods of correlation and regression analyses were applied. A wide range of the most important and most often used human potential assessment indicators based on a basic systemic classification of human potential will also be presented. Although the first glance the quality of human resources situation in Europe might seem relatively compact, deeper analysis showed that there are quite significant regional differences. Our results show that set of specific condition a constant or moderately growing human capital may aggravate the consequences of population ageing rather than alleviate them. The important results of this study include recognition of the existence of several easily manageable methods and ways of measuring demographic and/or socio-economic solutions to the challenges posed by quality of human resources in Europe.

Key words: Human capital, Spatial differentiation, Correlation and Regression analysis, Quality of life, Europe 